\title{
THE EFFECT OF VARYING PULMONARY PRESSURE ON THE ARTERIAL PRESSURES IN MAN AND ANESTHETIZED CATS ${ }^{1}$
}

\author{
BY RAYMOND J. DERN AND WALLACE O. FENN
}

(From the Department of Physiology of the School of Medicine and Dentistry of the University of Rochester, Rochester, N. Y.)

(Received for publication December 14, 1946)

Numerous observations of the effects of pressure breathing on the arterial blood pressure of anesthetized animals are available in the literature (1-7). In all cases an increase in the pulmonary pressure results in a fall of the arterial pressure (mean pressure as measured on a mercury manometer), with an occasional secondary compensatory rise.

With negative pulmonary pressures the effects are less regular, according to Schaefer and Bain (2), but usually the arterial pressure rises (7). Bruns (8) showed an increased stroke volume in a plethysmographic record of a rabbit heart during negative pressure breathing and Böger, Cobet, and Stepp (9) found an increased cardiac output of 15 to 162 per cent, and an increased oxygen consumption ( 37 per cent) with a negative pulmonary pressure of $5 \mathrm{~cm} . \mathrm{H}_{2} \mathrm{O}$ in a rabbit. Since these experiments were done on anesthetized animals it is difficult to apply them directly to the human problem.

Most measurements previously made on men are confined to brief periods of increased positive pressure such as may be obtained by the Valsalva experiments $(5,6,10-14)$. It has been generally found that with such an increase of intrapulmonary pressure the systemic arterial pressure rises briefly and then falls. This is followed by a secondary rise above the initial level. The secondary rise does not occur if the intrapulmonary pressure is too high. The heart rate usually accelerates. According to Bürger (13), only 3 out of 145 cases

\footnotetext{
1 This work was done under contract recommended by the Committee on Medical Research between the Office of Scientific Research and Development and the University of Rochester. The data included in this paper were obtained by the cooperative effort of a large group including Doctors Hermann Rahn, L. H. Chadwick, Arthur B. Otis, Lorin J. Mullins, R. E. Gosselin, and others who kindly served as subjects. Some of the other data from the same experiment have been published elsewhere (Rahn, Otis, et al, 1946 and Otis, Rahn, et al, 1946).
}

showed a slowing of the heart. Barach et al (15) recently reported a series of experiments on men breathing air at a constant pressure of $20 \mathrm{~cm} . \mathrm{H}_{2} \mathrm{O}$ in which he found a rise in arterial blood pressure equal approximately to the applied pulmonary pressure.

The effects of negative pressures in man were studied by $\mathrm{Kuhn}(16,17)$ who used a mask (Saugmaske) with a restricted inlet orifice and a large outlet. Because of the increased amount of blood in the lungs this was regarded as a useful type of therapy for tuberculosis. Evidence was also offered however to show that the volume of the pulse was increased. Later, Bruns $(8,18)$ concluded, mostly on the basis of similar evidence, that negative pulmonary pressure increases the cardiac output. He recommended negative pressure breathing for patients with poor venous return and certain types of heart disease. Subsequent investigators have paid little attention to this subject and the treatment has not been further investigated possibly because of the danger of dilating the heart or rupturing a vein in the thorax. One such case of dilated heart was recorded by Stigler (19) as a result of negative pressure breathing (man under water breathing surface air through a tube). The evidence concerning the physiological effects of this procedure in man is still fragmentary.

The experiments reported below were designed primarily to elucidate the problems of positive pressure breathing of possible military importance, but for the sake of completeness they were extended to cover negative pressures as well. The respiratory effects of these same procedures on our subjects were studied simultaneously and the results have been reported elsewhere (20).

\section{METHODS}

For the animal experiments, cats were anesthetized with dial. Mean arterial pressures were obtained by a carotid 
artery cannula connected to a recording mercury manometer. Simultaneous right auricular pressures were recorded by means of a sound inserted to the level of the heart through the jugular vein, activating a recording tambour. Peripheral venous pressures were measured on a saline manometer connected to a femoral vein cannula. The tracheal cannula was attached to a very short sidearm on a large rubber hose. One end of the hose was connected to a compressed air line for positive pressures or to a vacuum pump for negative pressure. In either technique air was passed through the hose rapidly enough to avoid rebreathing. Pressures were regulated by a pinch clamp on the end of the hose opposite to the pump. Intratracheal pressures were measured on a water manometer connected to a sidearm in the cannula. This system permitted the pulmonary pressure to be set at any value up to $40 \mathrm{~cm} . \mathrm{H}_{2} \mathrm{O}$, positive or negative, and the variation in pressure during the respiratory cycle was not over $\pm 3 \mathrm{~cm} . \mathrm{H}_{2} \mathrm{O}$. The animal board was constructed so that the animal could be tilted either head or feet down (45 degrees) without altering the position of the heart relative to the recording instruments.

In the experiments on humans, systolic and diastolic pressures were read partly by the usual auscultatory method but more often by the use of the Tycos recording sphygmomanometer. Heart rates were counted from the carotid pulse over a 30-second interval. Measurements were made, with the subjects in the supine and in the sitting positions. In the lying position, the subjects were in a Drinker respirator and the equivalent of a positive pulmonary pressure was obtained by a continuous negative pressure in the respirator. For the sitting position we used a "body box" with the head protruding through a rubber collar in the top, or a helmet with the bottom closed by a similar collar. When the subject was in the body box or the Drinker respirator the blood pressure in the arm was recorded outside the box. In this case the pressure as read was the pressure in relation to the pulmonary or atmospheric pressure as zero, not the pressure as related to that surrounding the arm. For the sake of uniformity, therefore, we added the differential pulmonary pressure to our readings. In the charts all the pressures are those which would be read in the arm in the usual way if the positive pressure had been applied to the head only by means of a helmet. The usual procedure was to increase or decrease the pulmonary pressure in steps of $8 \mathrm{~mm}$. $\mathrm{Hg}$, holding the pressure at each stage for from 5 to 8 minutes.

\section{RESULTS}

(1) Cat experiments. The data of 4 cat experiments are given in Figure 1. Abscissae represent the applied intrapulmonary pressure in $\mathrm{mm} . \mathrm{Hg}$; and the ordinates, the change in mean arterial pressure. Each determination with negative pressures was made over an interval of from 1 to 5 minutes. The determinations with positive pressures are open to question since each application

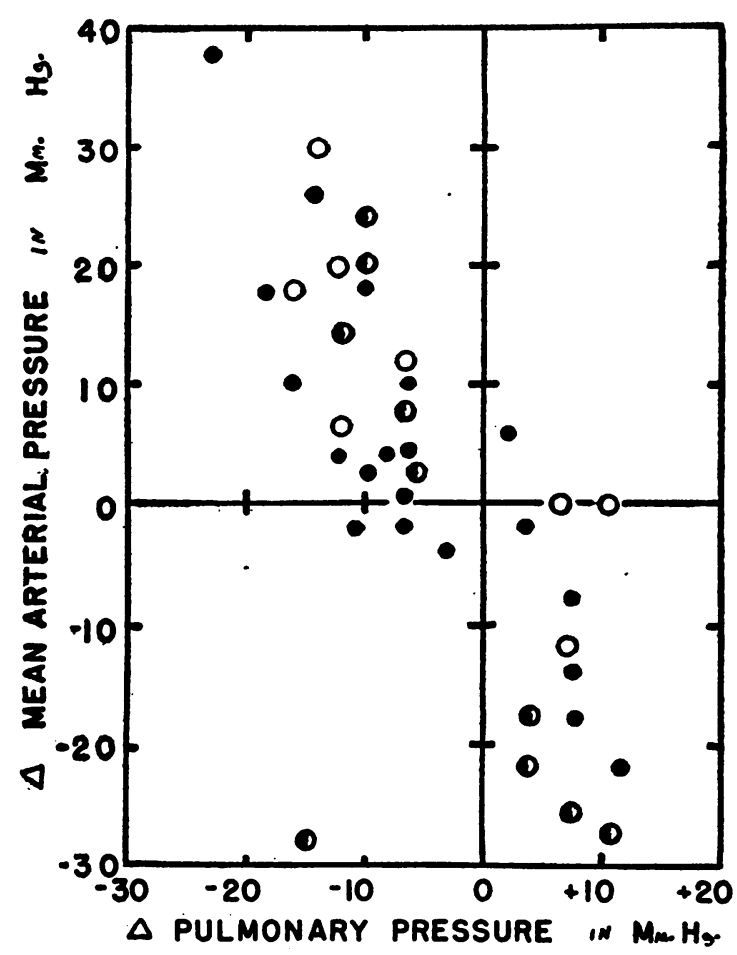

Fig. 1. The Change in the Mean Arterial Pressure of the Cat When the Intrapulmonary PresSURE IS ALTERED

Ordinates: The change in mean arterial pressure in millimeters of mercury.

Abscissae : The change in intrapulmonary pressure in millimeters of mercury.

Meaning of symbols: Open circles : Cat in head-down position. Half closed circles : Cat in feet-down position. Solid circles: Cat in horizontal position.

was brief due to threatened respiratory embarrassment and adequate time was probably not allowed for the compensatory rise found by others (2). With one exception negative pressures gave a rise in arterial pressure. With positive pressures, there is a tendency for the feet-up position to protect against a fall in arterial pressure and for the feet-down position to render the animal more susceptible to this effect. If true, this is presumably due to the effect of these positions on the venous return. The effect of negative pressures appears to be independent of the position of the animal. During the course of an experiment there was a slow but steady decline in arterial pressure. It was observed that negative pressures produced a greater rise in blood pressure if the arterial pressure was initially low, in general tending to restore the arterial pressure to normal. Shortly before 


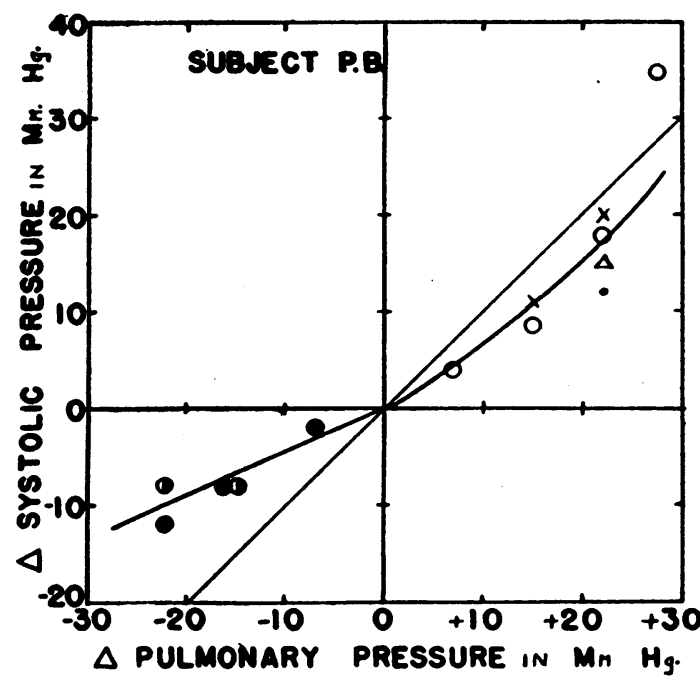

FIG. 2

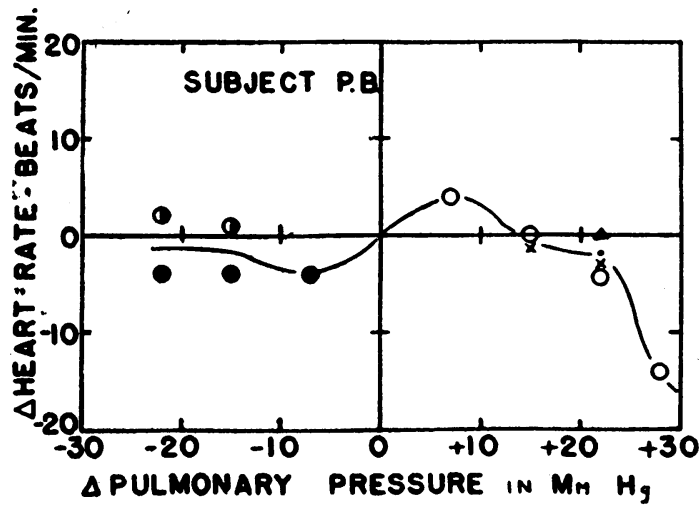

FIG. 4

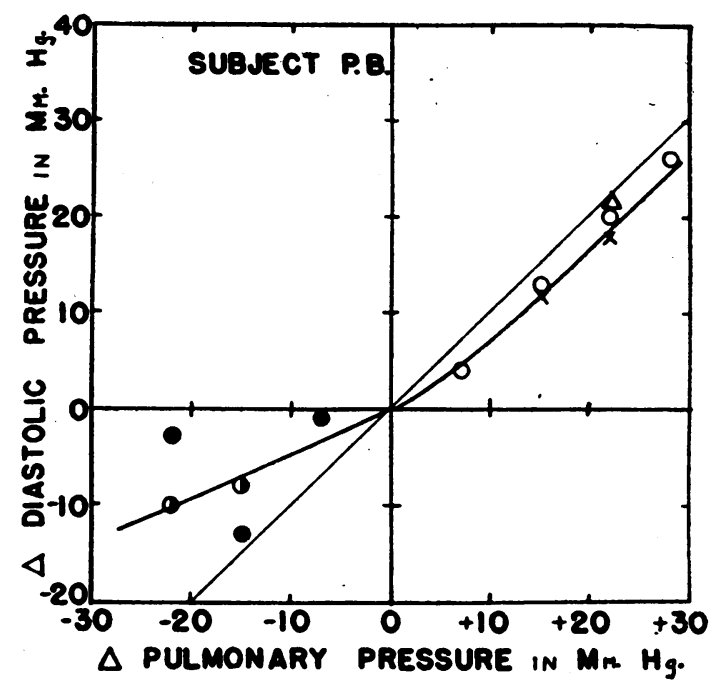

FIG. 3

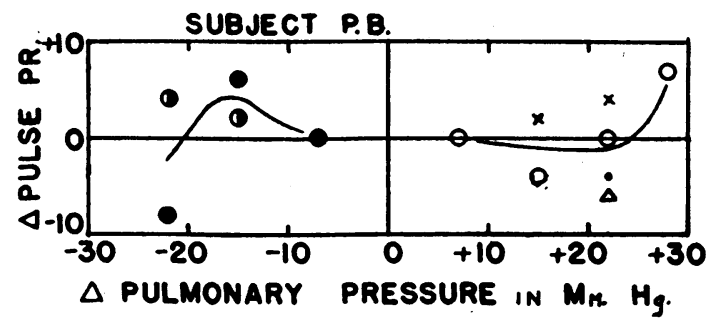

FIG. 5

FIGS. 2 through 5 . The changes in systolic blood pressure in $\mathrm{mm}$. $\mathrm{Hg}$, diastolic blood pressure in $\mathrm{mm}$. $\mathrm{Hg}$, the pulse pressure in $\mathrm{mm} . \mathrm{Hg}$, and heart rate in beats per minute for one subject in the sitting position in response to changes in intrapulmonary pressures. Abscissae: The change in intrapulmonary pressure in $\mathrm{mm}$. $\mathrm{Hg}$.

death, however, negative pressure failed to alter the arterial pressure.

Our venous pressure data in the cat will not be presented in detail because they confirm, in general, those of Holt (21). In both cases the auricular pressure falls by an amount equal to the decrease in pulmonary pressure: ${ }^{2}$ With increased pulmonary pressures in the dog, Holt found a rise in auricular pressure almost equal to the rise in applied pressure, but in our experiments on cats the rise was only about $1 / 2$ that of the pulmonary

2 This equality of pressures appears to indicate that the lung is more distensible when the volume and pressure are low than in the normal breathing range. pressure. Holt (22) and Otis et al (23) in their studies on man report a 50 per cent rise. The failure to obtain a greater rise has been explained by the absorption of part of the applied pulmonary pressure by the elasticity of lung tissue.

(2) Experiments on man. Typical results on one individual, P. B., in the sitting position are shown in Figures 2 through 5 . The changes in systolic pressure are plotted against the changes in the pulmonary pressure. It is evident that the systolic pressure rose with positive and fell with negative pulmonary pressures. A change in the blood pressure equal to the change in the pulmonary pressure is indicated by the straight diagonal 
lines passing through the origin. Since all (but one) of the points are below this line during positive pressure breathing it is evident that the systolic pressure does not follow completely the change in pulmonary pressure. However, the intrathoracic pressure does not rise quite so much as the pulmonary pressure because of the elasticity of the lungs; so it is probable that in this case the

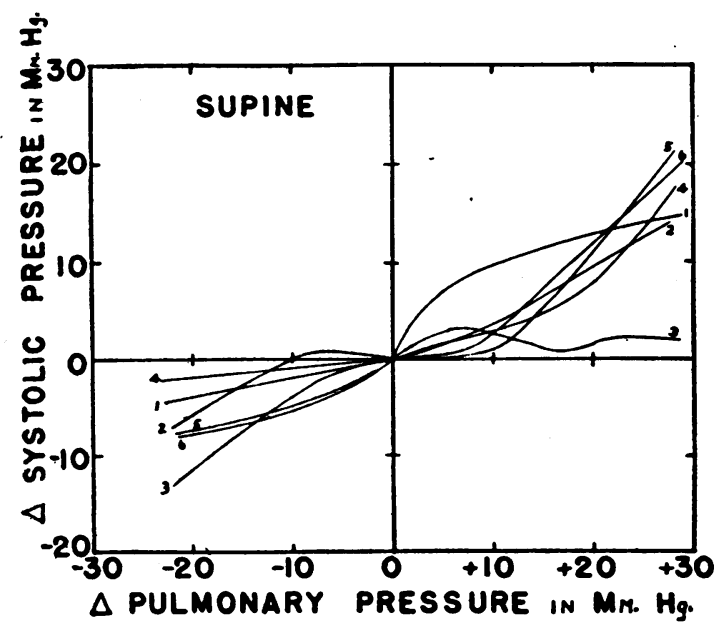

FIG. 6

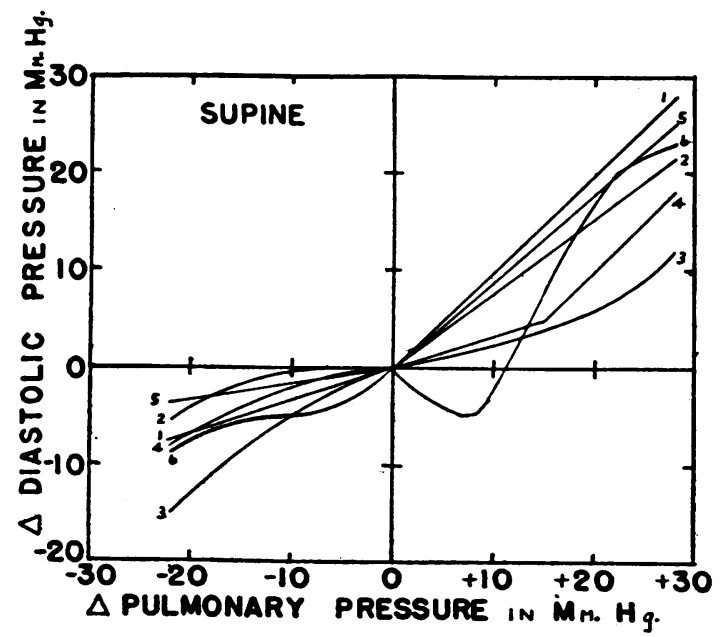

FIG. 8 systolic pressure is closely following the intrathoracic pressure. The changes in the heart rate of P. B. (Figure 4) were variable. On some days it increased and on other days it decreased under apparently comparable conditions. Similar variations were occasionally observed in other subjects.

In Figures 6 and 7 are shown curves for systolic pressures in other individuals in the sitting and the
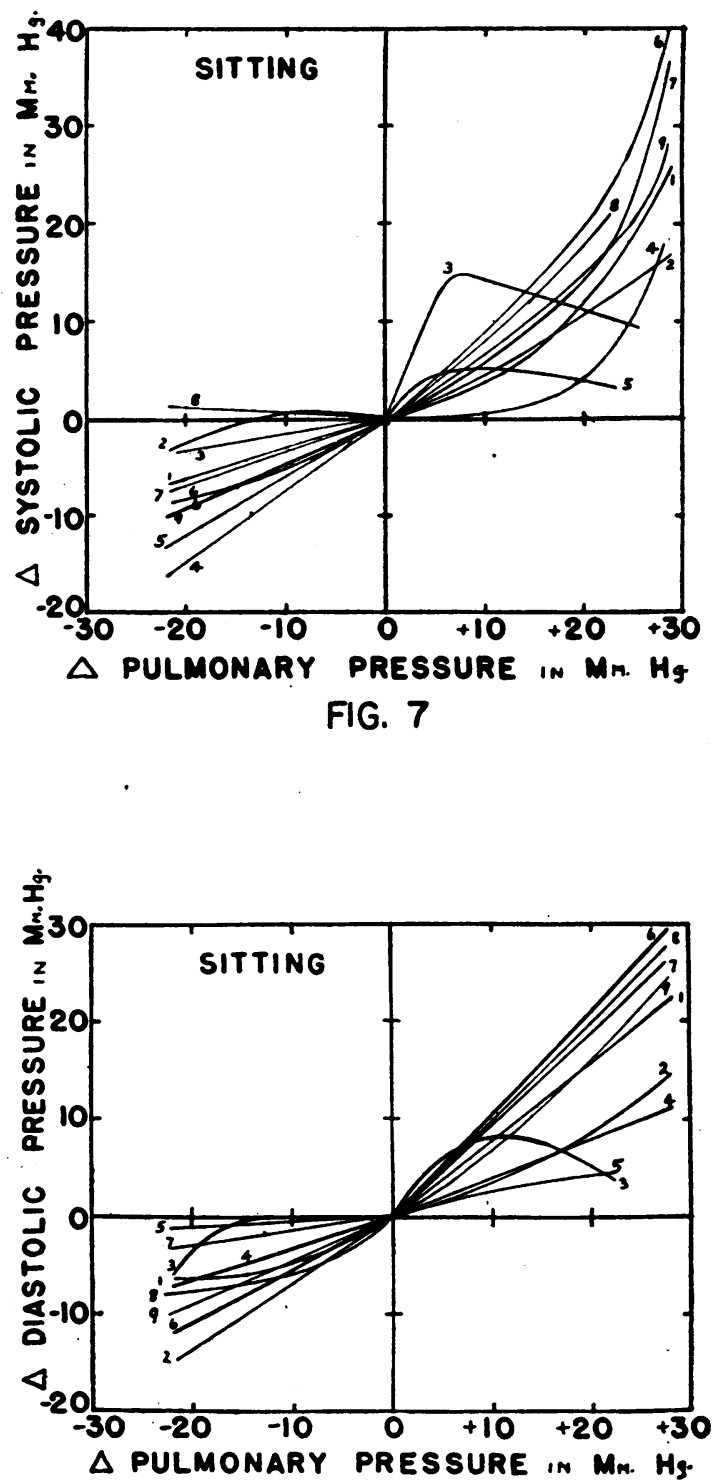

FIG. 9

Figs. 6 through 9. The changes in systolic and diastolic blood pressure in response to a change in applied pulmonary pressure. Figures 6 and 8 are for the supine position; Figures 7 and 9 are for the sitting position. Ordinates: Figures 6 and 7, the change in systolic pressure in mm. Hg. Figures 8 and 9, the change in diastolic pressure in $\mathrm{mm}$. Hg. Abscissae: The change in applied pulmonary pressure in $\mathrm{mm}$. $\mathrm{Hg}$. Each curve is for a single subject. Numbers on the graph identify the different subjects. 
supine positions respectively. The numbers on the curves refer to the numbers of the subjects. Different subjects were used however for the two series so that similar numbers in the two series do not refer to the same subjects. All the subjects were members of the staff or medical students, and all were in normal health. The corresponding diastolic pressures in these same experiments are shown in Figures 8 and 9 . The numbers of the subjects in Figures 6 and 8 correspond, as do those in Figures 7 and 9. The general result obtained in all these experiments is very evident. Positive pressures increase and negative pressures decrease both systolic and diastolic pressures. An occasional exception occurs.

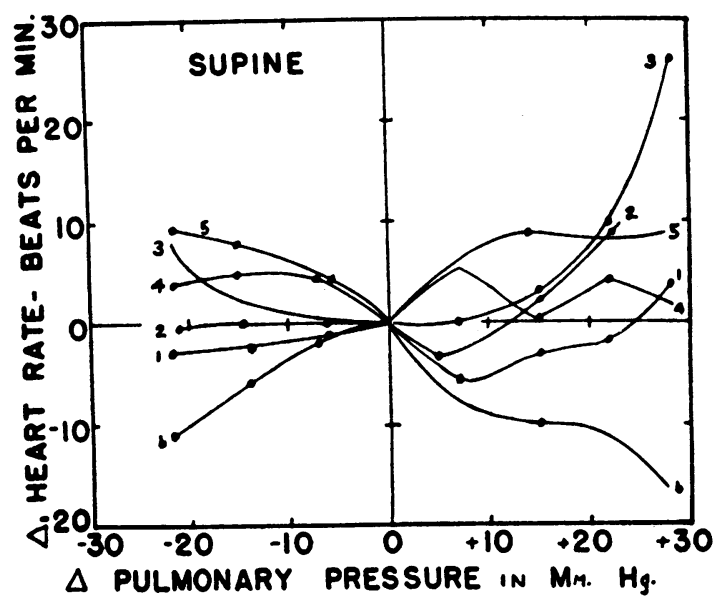

FIG. 10

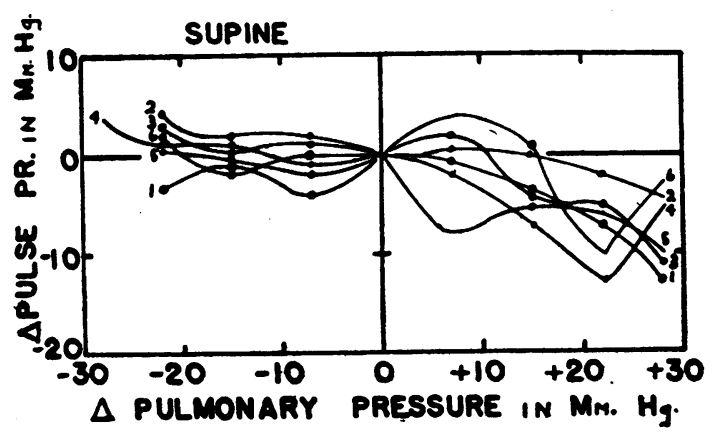

FIG. 12
The curves in Figures 6 to 9 were drawn to give a reasonable fit to the scatter of points obtained with each individual as indicated for P. B. in Figures 2 to 5 . To avoid confusion the individual points are not given. Details of the curves often represent only single points and are of no significance. At the highest pressures of $28 \mathrm{~mm}$. $\mathrm{Hg}$ the systolic pressures seem unduly high in many cases. We did not usually leave the subjects very long at this pressure and the high reading may be only an initial effect due to the excitement. When the pulmonary pressure reaches a point where the venous filling pressure is no longer able to compensate, the arterial pressure would of course be low. In subject No. 3 in the sitting position (Fig-

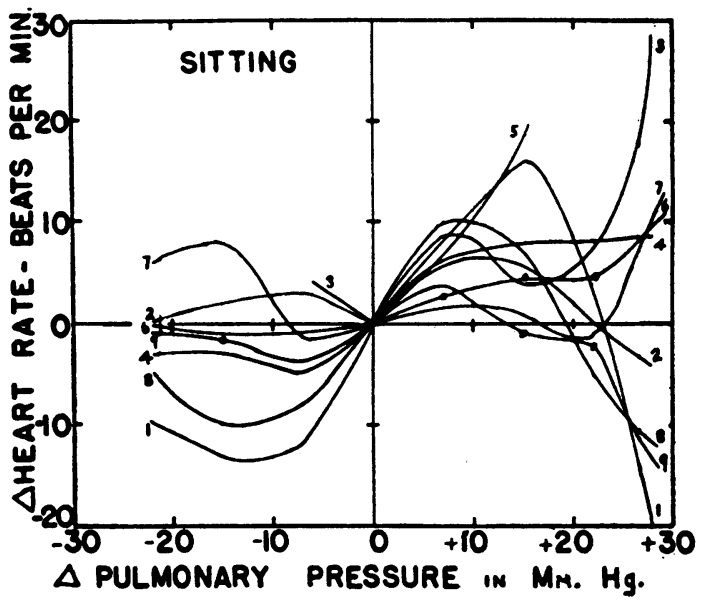

FIG. II

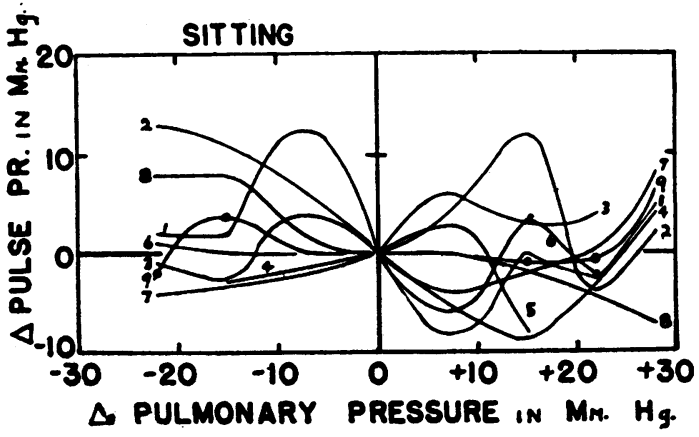

FIG. 13

FIGs. 10 through 13. The change in heart rate and pulse pressure in response to a change in applied pulmonary pressure. Figures 10 and 12 are for the supine position; Figures 11 and 13 are for the sitting position. Ordinates: Figures 10 and 11, the change in heart rate in beats per minute. Figures 12 and 13, the change in pulse pressure in $\mathrm{mm}$. $\mathrm{Hg}$. Abscissae: The change in applied pulmonary pressure in $\mathrm{mm}$. $\mathrm{Hg}$. Each curve is for a single subject identified by the number on the graph. 
ures 7 and 9) we actually found an arterial pressure too low to give any readable deflection in the record. This occurred just before the subject had to be relieved of the pressure because of a threatened collapse. It was generally observed that the subject's blood pressure reached an equilibrium for a given pulmonary pressure within 1 minute after its application. It was also noted that in those subjects who nearly collapsed the blood pressure was maintained at its normal level until a minute or two before the onset of severe distress

A comparison of Figures 6 and 7 shows that with positive pressures the systolic blood pressure rises to a higher level in the sitting than in the supine position for an equal increment of pulmonary pressure. However, the average diastolic pressures for both positions follow roughly the intrathoracic pressure although the variation is large. This results in a decrease in the average pulse pressure in the supine position but no change in the sitting position. The various explanations suggested for these facts may be omitted here as purely speculative.

Changes in heart rate in the sitting and the supine positions are shown in Figures 10 and 11 respectively. The numbers represent subjects as before. Numbers in Figures 10 and 12 correspond to those in Figures 6 and 8 . In these figures the graphs are drawn through the actual points or the average points (where 2 or more observations were available). Such average points are indicated by dots on the curves. Detailed variations are of no significance, but it may be noted that, in the sitting position especially, there is a rather pronounced tendency in some subjects toward a decreased heart rate at the higher pressures. When the subject became alarmed at these high pressures or was about to collapse the rate might have gone high. (See curves for subject No. 3 in Figure 11.) Low heart rates have usually been attributed to increased intracerebral pressure and the absence of an acceleration due to excitement and effort or to a less sensitive carotid sinus which would not respond to a decreased pulse pressure. The incidence of low heart rates with increased pressure is much higher in our series than that reported by Bürger (13). Most individuals gave the same characteristic response on successive days, either a rise or a fall, but some gave an increase one day and decrease the next without apparent cause.
In the sitting position, at least, there is no consistent change in pulse pressure as can be seen from the average curves for 8 subjects shown in Figure 13. In the supine position however there appears to be a slight decrease of 10 or 15 per cent at the extreme pressure of $30 \mathrm{~mm}$. $\mathrm{Hg}$ (Figure 12). This is consistent with the observation of a slightly decreased cardiac output (24).

\section{DISCUSSION}

Since our results with human subjects show that the arterial pressure follows approximately the intrapleural pressure (whether positive or negative) it may be argued either (1) that the explanation is purely mechanical, i.e. the arterial pressure is higher simply because the initial pressure in the ventricle was higher before systole began, or (2) that the blood pressure level is regulated reflexly by afferents arising from structures such as those around the aorta, which are exposed to the variations in intrapleural pressure. Such structures would respond in such a way as to maintain a constant difference between arterial and intrapleural pressure. Central structures within the brain itself would presumably behave in the same way since the pressure of the cerebrospinal fluid varies closely with the intrapleural pressure (Hamilton, Woodbury and Harper, 25). In our experiments with either helmet or body box the carotid sinus was exposed exteriorly to a pressure equal to the pulmonary pressure. If this organ were solely responsible for the regulation of the level of the arterial pressure, it would have kept the level of the blood pressure constant relative to the pulmonary pressure. Actually, the blood pressure is more nearly constant relative to intrathoracic pressure which increases somewhat more than half as much as the pulmonary pressure. Furthermore, Barach et al (15) have shown that when pressure is applied by mask, the arterial pressure remains constant relative to the pulmonary pressure. With their technique, the carotid sinus is not affected by the applied pulmonary pressure but is exposed through the skin to atmospheric pressure at all times. Its presumed effect would therefore be to control the arterial pressure at a level which is constant relative to atmospheric pressure. Since, in both techniques, the expected carotid sinus effect is apparently absent, it may be concluded that the carotid sinus is in- 
sensitive to a rise in arterial pressure of at least 15 $\mathrm{mm}$. $\mathrm{Hg}$ or to a fall of at least $10 \mathrm{~mm}$. $\mathrm{Hg}$, or that it is dominated by other receptors.

The ability of an individual to maintain pulmonary pressure has been used as a test of right ventricular fitness $(6,10,11,13,26)$ on the theory that pressure increases the resistance of the pulmonary circuit. This is borne out by the work of Heinbecker (27) who perfused lungs in an artificial thorax. When they were inflated by negative pressure in the thorax, the flow increased but when they were inflated by positive intrapulmonary pressure the flow was decreased. No heart was included in this circuit so that inflow and outflow pressures were constant, and the result can clearly be attributed to the enlargement or diminution in the size of the vessels due to the respective increase or decrease in mean pressure surrounding them. When the heart is included in the circuit the situation is more complex because the heart is also exposed to the intrathoracic pressure. The immediate effect of pressure changes on the flow depends upon the capacity of the lungs $(28,29)$ which varies greatly with pressure, but in general the decrease in pulmonary resistance with negative pressure inflation is confirmed (30). In these experiments, however, the venous pressure remained constant while in the body this is not the case and the flow through the pulmonary circuit depends more upon the filling of the heart than upon the pulmonary resistance. This is especially true when the intrapulmonary pressure is maintained higher or lower than normal more or, less indefinitely so that the capacity of the lung vessels can reach a steady state value.

The filling of the heart depends of course upon the venous pressure which in man appears to follow the intrapleural pressure with remarkable promptness and fidelity (23). With positive pressure the venous return is therefore well maintained although there is evidence of a slight decrease in cardiac output $(15,24)$. This is indicated indirectly also by the rise of arterial pressure in man with increased intrapulmonary pressure. In the anesthetized cats, however, where the arterial pressure fell, the inflow into the heart must have diminished as it does in anesthetized dogs (31). Conversely in the cats a rise of arterial pressure was observed with negative pressure breathing indicating that the venous return was improved. In man the absence of such an increase in arterial pressure suggests that the normal venous pressure was adequate to fill the heart to its limit so that further increases of the pressure gradient had no further effect. The fall in arterial pressure which we have observed in man with negative pulmonary pressures lends no support to the idea that this procedure increases cardiac output and would therefore be beneficial, but it does not contradict this possibility. Since we have observed a diminished pulse volume during positive pressure breathing it seems probable that an increase in pulse volume occurs in negative pressure breathing as has previously been reported $(17,8,32)$. Böger et al (9) found the heart rate decreased in anesthetized rabbits but Bruns (18) found it mostly increased in man. It is possible, therefore, that with negative pressure breathing there is a slight increase in the cardiac output just as, with positive pressure, there is, if anything, a slight decrease $(15,24)$. Such an increase would be particularly likely to occur in any condition in which the venous return was initially defective. Further work on the effects of negative pulmonary pressures is needed to verify this interpretation of our results.

\section{SUMMARY}

1. The response of the systolic and diastolic pressures and heart rate of man, and of the mean arterial, right auricular, and femoral venous pressures of the anesthetized cat, to increased and decreased intrapulmonary pressure was studied. Body position was àlso varied.

2. In the cat, mean arterial pressures rise in response to a decreased pulmonary pressure, independently of the position of the animal. With increased pulmonary pressure only the primary fall of arterial pressure was studied, and this was much less in the head down than in the feet down position. Holt's (21) venous pressure observations were confirmed.

3. In man, in both supine and sitting positions, increased intrapulmonary pressure gave an increase in both systolic and diastolic pressures, and decreased intrapulmonary pressure gave a fall in both.

4. Pulse pressures in many were variable $( \pm 10$ $\mathrm{mm} . \mathrm{Hg}$ ) and tended to give a consistent decrease only with positive intrapulmonary pressure in the supine position. 
5. Heart rates were variable ( \pm 10 beats per minute).

6. If increased intrapulmonary pressure produced circulatory failure, arterial pressures and heart rates were maintained until within a minute or two of the onset of severe symptoms.

7. The effect of pressure breathing on blood pressure regulatory receptors is discussed.

\section{BIBLIOGRAPHY}

1. Chillingworth, F. P., and Hopkins, R., Physiologic changes produced by variations in lung distention. Am. J. Physiol., 1920, 51, 289.

2. Schafer, E., and Bain, W. A., The effects of changes in intrapulmonary air-pressure on the pulmonary and aortic circulation of the dog. Quart. J. Exper. Physiol., 1932, 22, 101.

3. Humphreys, G. H., Moore, R. L., and Barkley, H., Studies of the jugular carotid and pulmonary pressures of anesthetized dogs during positive inflation of the lungs. J. Thoracic Surg., 1939, 8, 553.

4. Ferguson, J. K. W., Changes in respiration on inflation and deflation of the chest. Am. J. Physiol., 1940, 130, 675.

5. Bruck, E., Uber den Blutdruck bei plötzlichen starken Anstrengungen und beim Valsalvaschen Versuch nebst Untersuchungen über die hierbei eintretenden Veränderungen der Herzgrösse. Deut. Arch. f. Klin. Med., 1907, 91, 171.

6. Bürger, M., Uber die Bedeutung des intrapulmonalen Drucks für den Kreislauf und den Mechanismus des Kollapses bei acuten Anstrengungen. Klin. Wochenschr., 1926, 5, 777 and 825.

7. Rost, E., Beitrag zur Kenntnis der Kreislaufverhältnisse bei Wiederbelebung durch Veränderung des intrapulmonalen Druckes. Ztschr. f. d. ges. exper. Med., 1932, 82, 255.

8. Bruns, O., Die weitere Ausgestaltung der Unterdruckatmung für die Behandlung der Kreislauf und Atmungsstörungen. Med. Klinik, 1913, 42, 1714.

9. Böger, A., Cobet, R., and Stepp, W., Experimentelle Untersuchungen zur Frage der Steigerung der Herzleistung durch Unterdruckatmung. Arch. f. exper. Path. u. Pharm., 1931, 160, 329.

10. Warner, E. C., and Hambley, W. D., An investigation into the physiological basis of the U-tube manometer test. The physical fitness of men assessed by various methods. Guy's Hosp. Rep., 1925, 75, 286 and 388.

11. Flack, M., Tests for flying efficiency and flying strain. Med. Res. Council. Special Report, 1920, 53, 95.

12. Böger, A., Uber die Einwirkung der Pressatmung auf den Kreislauf. Arch. f. exper. Path. u. Pharm., 1932, 166, 101

13. Bürger, M., Bürger, H., and Petersen, P. F., Die Pressdruckprobe als Herzleistungsprüfung. Arbeitsphysiol., 1929, 1, 614.

14. Petersen, P. F., Zur Frage des plötzlichen Ertrin- kungstodes. Ztschr. f. d. ges. exper. Med., 1928, $61,390$.

15. Barach, A. L., Eckman, M., Ginsburg, E., Rumsey, C. C., Jr., Kor, I., Eckman, I., and Besson, G., Studies on positive pressure respiration. J. Aviation Med., 1946, 17, 290.

16. Kuhn, E., Eine Lungensaugmaske zur Erzeugung von Stauungshyperämie in den Lungen. Deut. Med. Woch., 1906, 32, 1486.

17. Kuhn, E., Weitere Erfahrungen mit der Hyperämiebehandlung der Lungen vermittels der Lungen Saugmaske. Munch. Med. Woch., 1907, 54, 782.

18. Bruns, $O$., Die kunstliche Luftdruckniedrigung über den Lungen. Munch. Med. Woch., 1910, 57, 2169.

19. Stigler, R., Die Kraft unserer Inspirationsmuskulatur. Pflüg. Arch. für ges. Physiol., 1911, 139, 234.

20. Rahn, H., Otis, A. B., Chadwick, L. E., and Fenn, W. $\mathrm{O}$., The pressure-volume diagram of the thorax and lung. Am. J. Physiol., 1946, 146, 161.

21. Holt, J. P., The collapse factor in the measurement of venous pressure. Am. J. Physiol., 1941, 134, 292.

22. Holt, J. P., The effect of positive and negative intrathoracic pressure on peripheral venous pressure in man. Am. J. Physiol., 1943, 139, 208.

23. Otis, A. B., Rahn, H., and Fenn, W. O., Venous pressure changes associated with positive intrapulmonary pressures. Their relationship to the distensibility of the lung. Am. J. Physiol., 1946, 146, 307.

24. Otis, A. B., Rahn, H., Brontman, M., Mullins, L. J., and Fenn, W. O., Ballistocardiographic study of changes in cardiac output due to respiration. J. Clin. Invest., 1946, 25, 413.

25. Hamilton, W. F., Woodbury, R. A., and Harper, Jr., H. T., Physiologic relationships between intrathoracic, intraspinal and arterial pressures. J. A. M. A., 1936, 107, 853.

26. Bürger, M., Uber die Bedeutung des intrapulmonalen Drucks für den Mechanismus des Kollapses bei acuten Anstrengungen. Zeit. exper. Med., 1925, $52,321$.

27. Heinbecker, P., The mechanism of the respiratory waves in systemic arterial blood pressure. Am. J. Physiol., 1927, 81, 170.

28. Laux, L., Uber den Anteil der Kapazitäts und der Widerstandsänderungen der Lungenbahn an den respiratorischen Schwankungen der Stromstärke. Arch. f. d. ges. Physiol., 1930, 224, 110.

29. Shuler, R. H., Ensor, C., Gunning, R. E., Moss, W. G., and Johnson, V., The differential effects of respiration on the left and right ventricles. Am. J. Physiol., 1942, 137, 620.

30. Daly, deBurgh I., Resistance of the pulmonary vascular bed. J. Physiol., 1930, 69, 239.

31. Herrick, J. F., Code, C. F., MacLean, A. R., and Mann, F. C., Vascular changes associated with short periods of raised intrapulmonary pressures. Fed. Proc., 1942, 1, 39.

32. Bruns, O., Ziele und Erfolge der Behandlung von Kreislaufstörungen mit Unterdruckatmung. Deut. Med. Woch., 1911, 37, 2214. 